\title{
Preise für hervorragende Akte auf dem Gebiet der Gesetzgebung
}

Die Deutsche Gesellschaft für Gesetzgebung e. V. (DGG) verleiht mit finanzieller Unterstützung der Stiftung Apfelbaum - Lernprojekt für Ko-Evolution und Integration - zum zweiten Mal Preise für hervorragende Akte auf dem Gebiet der Gesetzgebung in Höhe von $€ 5.000$ (1. Preis), € 3.000 (2. Preis) und € 2.000 (3. Preis).

Ziel der Auslobung des Preises ist, die Qualität gesetzgeberischer Akte zu fördern. Für die Vergabe des Preises ist von der Deutschen Gesellschaft für Gesetzgebung eine Jury benannt worden, deren Mitglieder sind: Gerda Hasselfeldt, Vizepräsidentin des Deutschen Bundestages; Hans-Günter Henneke, Hauptgeschäftsführer beim Deutschen Landkreistag; Günter Krings, Vorsitzender der Deutschen Gesellschaft für Gesetzgebung e.V.; Hans-Jürgen Papier, Präsident des Bundesverfassungsgerichts; Werner Schnappauf, Hauptgeschäftsführer des Bundesverbandes der Deutschen Industrie sowie Rupert Scholz, Bundesminister a. D.

Eingesandt werden können beispielsweise: ein gutes Gesetz, ein guter Gesetzentwurf oder besonders gelungene Teile eines Gesetzentwurfes, ein alternativer Gesetzentwurf, ein Gesetzentwurf oder Vorschlag zur Vereinfachung eines Gesetzes, ein ausgeführter Vorschlag für eine methodische Innovation in der Gesetzgebung oder eine erfolgreich durchgeführte Gesetzesfolgenabschätzung.

Die Einsendung soll den preiswürdigen Akt auf dem Gebiet der Gesetzgebung, eine kurze Begründung der Preiswürdigkeit, den oder die Urheber des Aktes beziehungsweise den möglichen Empfänger des Preises sowie das ausgefüllte Nominierungsformular (erhältlich unter www.dggev.de) enthalten.

Selbstbewerbungen sind zulässig. Einsendeschluss ist der 31. Oktober 2008. Der preiswürdigen Akt und die Begründung werden dreifach erbeten.

Bewerbungen und gegebenenfalls Rückfragen sind an den Vorsitzenden der DGG zu richten: Dr. Günter Krings, MdB, Platz der Republik 1, 11011 Berlin, Telefon: (030) 227 73 061, E-Mail: info@dggev.de. Der Rechtsweg ist ausgeschlossen.

\section{Die Verfassung der Demokratien. Gemeinsame Tagung der Deutschen Vereinigung für Politische Wissenschaft, der Österreichischen Gesellschaft für Politikwissenschaft und der Schweizerischen Vereinigung für Politische Wissenschaft vom 21. bis 23. November 2008 in Osnabrück}

Freitag, 21. November 2008

13.00 bis $17.30 \mathrm{Uhr}$

Informationstag für junge Politikwissenschaftler: „Promotion - und was dann?“

\subsection{0 bis $14.30 \mathrm{Uhr}$}

Plenum: „Promotionsmöglichkeiten und Berufsperspektiven in Deutschland, Österreich und der Schweiz" mit Vertretern der DVPW, ÖGPW und SVPW;

„Karriereorientierung und Karriereplanung von Nachwuchswissenschaftler/innen. Eine Studie auf Initiative der DVPW“, Präsentation: Heike Kahlert, Mark Kleemann und Doreen Kruppa, Universität Rostock 